\title{
Acción comunicativa y el proceso constituyente boliviano*
}

\author{
Communicative action and the bolivian \\ constituent process
}

\section{Boris Wilson Arias López**}

Artículo reflexión

Fecha de Recepción: 12 de enero de 2021

Fecha de Aceptación: 28 de febrero de 2021

\section{Para citar este artículo:}

Arias López, B. W. (2021). Acción comunicativa y el proceso constituyente boliviano. Revista Análisis Jurídico-Político, 3(5), 143-167. https://doi.org/10.22490/26655489.4515

\section{Resumen}

El presente trabajo observa el proceso constituyente boliviano desde la teoría de la acción comunicativa planteada por el profesor Jürgen Habermas, analizándose para ello: 1) al titular del poder constituyente, lo que denota el grado de participación; 2) las temáticas admisibles que deben tratarse en la asamblea constituyente,

\footnotetext{
* El artículo deviene de las reflexiones efectuadas durante la elaboración de la tesis doctoral titulada: Principios rectores para la interpretación de la Constitución cultural boliviana, que el autor del artículo efectúa en la Universidad Mayor de San Andrés, La Paz, Bolivia. ** Magíster en Derecho Constitucional y Recursos Constitucionales por la Universidad Andina Simón Bolívar. Docente investigador titular de la Universidad Mayor de San Andrés, La Paz, Bolivia. oRCID: https://orcid.org/0000-0001-6891-7606 Correo electrónico: barias@ umsa.bo y borisito55@hotmail.com.
} 
lo que muestra el grado de imposición; y 3) el procedimiento traumático utilizado y que concluye con la Constitución del año 2009.

En este sentido, se espera mostrar que la falta de debate racional en la asamblea constituyente boliviana, luego de que esta fuera aprobada, impidió tener un significado compartido; es decir, que la falta de orden y buena fe en el debate proyectó y generó incertidumbre en la interpretación constitucional, incluso por órganos especializados en ese tipo de interpretación, como son la Asamblea Legislativa Plurinacional y el Tribunal Constitucional Plurinacional, de forma que determinar el significado del texto constitucional para el ciudadano es incluso mucho más dificultoso e incierto.

Palabras clave: acción comunicativa, Bolivia, interpretación, proceso constituyente, teoría impura del derecho.

\section{Abstract}

This paper observes the Bolivian constituent process from the theory of communicative action planted by Professor J. Habermas, analyzing for it: 1 . the holder of the constituent power, which denotes the degree of participation, 2. the admissible topics to be covered in the constituent assembly which denotes the degree of imposition, and 3. the traumatic procedure used and which concludes with the 2009 Constitution.

In this sense, it is expected to show that the lack of rational debate in the Bolivian constituent assembly, after it was approved, prevented having a shared meaning, that is, that the lack of order and good faith in the debate projected and generated uncertainty in constitutional interpretation, even by specialized bodies in this type of interpretation, such as the Plurinational Legislative Assembly and the Plurinational Constitutional Court, so that determining the meaning of the constitutional text for the citizen is even much more difficult and uncertain

Keywords: Bolivia; Communicative action; Constituent process; Impure theory of law; Interpretation. 


\section{INTRODUCCIÓN A LA TEMÁTICA}

Con el denominado giro lingüístico propiciado por Ludwig Wittgenstein, básicamente se entendió que si solo se puede pensar con el lenguaje, entonces, el lenguaje constituye el límite del pensamiento. Desde entonces, parte de la filosofía dejó de centrarse en la metafísica y su paradigma fue el lenguaje.

En este contexto, la teoría de la acción comunicativa de Jürgen Habermas intenta unir la racionalidad y el lenguaje; es decir, que el debate racional mediado por el lenguaje permite alcanzar consensos racionales motivados, lo que genera un lenguaje de naturaleza racional ${ }^{1}$. De esta forma, el profesor alemán pretende explicar el paso de lo subjetivo a lo intersubjetivo, partiendo de la idea de que el lenguaje racional permite al hombre salir del solipsismo y coordinar sus acciones. Esto significa que pasa a la "intersubjetividad", de manera que la "relación" sustituye al "ser"2.

Ahora bien, básicamente para Habermas el lenguaje sirve para: 1) describir el mundo; y 2) dirigir las conductas. En lo referido a las prescripciones jurídicas, se tiene que la acción comunicativa entiende que una norma compuesta por palabras no solo ordena, sino que al mismo tiempo es explicativa. Es decir, que para prescribir se necesita comprender, y para comprender primero se necesita analizar y criticar, de donde resultará un lenguaje racional y público en la medida en la que es compartido racionalmente ${ }^{3}$.

\footnotetext{
1 "Para la racionalidad de la manifestación es esencial que el hablante plantee en relación con su enunciado $\mathrm{p}$ una pretensión de validez susceptible de crítica que pueda ser aceptada o rechazada por el oyente" (Habermas, 1988).

2 “El lenguaje es instrumento de socialización y de autoconstitución del individuo. La comunicación proporciona un trasvase permanente de lo colectivo a lo individual y de lo individual a lo colectivo" (Boladeras, 1996).

3 “El empleo del lenguaje orientado al entendimiento, del que depende la acción comunicativa, funciona del siguiente modo: los participantes, a través de la validez que pretenden para sus actos de habla, o bien se ponen de acuerdo, o bien constatan disentimientos que en el curso posterior de la interacción los participantes tienen en cuenta de común acuerdo. Con todo acto de habla se entablan pretensiones de validez susceptibles de crítica, que se enderezan a un reconocimiento intersubjetivo" (Habermas, 2010).
} 
Cuando una constitución impone un lenguaje meramente emotivo o plagado de vaguedad ${ }^{4}$ emergente de un procedimiento sin previo debate y sin la posibilidad de crítica, entonces, el lenguaje no permite comunicación entre el emisor y el receptor. Para el profesor alemán este no puede ser considerado legítimo ${ }^{5}$.

En el presente trabajo se examinará la calidad del debate en el proceso de reforma constitucional boliviano y cómo influyó en el contenido de la Constitución. En este sentido, se defenderá la idea de que la mayor dificultad para afrontar un debate serio sobre la interpretación de la Constitución boliviana es precisamente la falta de acción comunicativa. A efecto de estudiar la racionalidad del proceso constitucional boliviano de 2009, se observará lo siguiente: 1) la amplitud de los sujetos que participaron; 2) las temáticas admisibles que debían tratarse; y 3) el procedimiento utilizado. El análisis referido pretende mostrar deficiencias en el debate democrático que dio lugar a la Constitución boliviana del año 2009, lo que impide conocer gran parte del contenido del texto constitucional.

\section{LA IDEA DE PUEBLO COMO TITULAR DEL PODER CONSTITUYENTE}

La teoría del poder constituyente implica el desarrollo del derecho de un pueblo a gobernarse, y para el estudio de esta teoría se debe considerar lo siguiente:

- que el pueblo es en realidad el titular de la soberanía;

- dicho poder se expresa una sola vez;

- y el ejercicio de este poder crea una norma llamada constitución.

4 Afecta a la teoría más que al lenguaje.

5 "Que algo sea 'racional para mí' significa que he hecho mías normas a cuya luz tiene 'pleno sentido' o está 'indicado', es 'plausible' o simplemente es 'lo mejor' creer, sentir o hacer algo [...] Las normas morales determinan en qué casos es racional para los integrantes de la comunidad avergonzarse, sentirse culpable o indignarse por el comportamiento de otros [...]" (Habermas, 1999). 
Si partimos de la idea de soberanía nacional de Sieyes, entonces los representantes en la asamblea constituyente no necesitan referéndum para aprobar una constitución; en cambio, si partimos de la concepción estadounidense, donde los asambleístas no representan al pueblo, el proyecto de constitución que elaboran requiere la confirmación del pueblo, por lo tanto, un referéndum aprobatorio; ¿cuál de las dos visiones prevaleció en la asamblea constituyente boliviana? ${ }^{6}$.

$\mathrm{Al}$ respecto, consideremos la Sentencia Constitucional Plurinacional n. ${ }^{\circ}$ 0084/ 2017 de 28 de noviembre, del Tribunal Constitucional Plurinacional correspondiente a una demanda de inconstitucionalidad que declaró inaplicables los artículos 156, 168, 285.II y 288 de la Constitución Política del Estado de Bolivia en las frases: “[...] por una sola vez de manera continua", de los artículos 156 y 168, y "[...] de manera continua por una sola vez", de los artículos 285.II y 288, habilitando de esta forma la repostulación del presidente de ese entonces, de manera indefinida, pese a la prohibición del texto constitucional.

El órgano de control de constitucionalidad en la referida decisión utilizó, entre otros argumentos, la idea de que la asamblea constituyente boliviana fue de naturaleza originaria, por lo tanto, absoluta; entonces, analizó las actas de la comisión, que se decantó por una reelección presidencial indefinida en los siguientes términos:

En relación al contenido de lo que ahora es el artículo 168 de la CPE, se consigna el siguiente texto: "El periodo de mandato de la Presidenta o del Presidente y de la Vicepresidenta o del Vicepresidente del Estado es de cinco años, y pueden ser reelectas o reelectos por una sola vez de manera continua."; no

6 La idea romántica sostenida por los profesores de Derecho Constitucional, en sentido de que con el poder constituyente el poder vuelve al pueblo por lo que resulta superflua la división de poderes, es absurda y peligrosa, como sucede en Venezuela, donde la todopoderosa asamblea constituyente convocada por el presidente Nicolás Maduro derroca sin mayor limitación a los funcionarios democráticamente elegidos, y apartarse de limitaciones legales, en los hechos, no es otra cosa que un instrumento de gobierno del autoritarismo. Al respecto, David Landau desarrolla la idea de constitucionalismo abusivo en estos términos: "El constitucionalismo abusivo implica el uso de los mecanismos de reforma constitucional —la reforma constitucional y la sustitución constitucional — para socavar la democracia [...]" (Landau, 2015). 
obstante, a los efectos de cumplir el mandato constitucional en relación a la aplicación de los criterios de interpretación del Texto Constitucional y a objeto de establecer, cuál ha sido la voluntad del constituyente en relación a lo que concierne a las normas consignadas en dicho artículo, corresponde remitirse a los documentos, actas y resoluciones de la Asamblea Constituyente, cuya Comisión 7 encargada del órgano ejecutivo, en relación al mismo, en su Informe por mayoría, consigna la siguiente redacción: "La Presidenta o Presidente y Vicepresidenta o Vicepresidente, podrán ser reelectos consecutivamente por voluntad del pueblo". (Tribunal Constitucional Plurinacionalista, Sentencia 0084)

Para concluir que la voluntad de la asamblea constituyente originaria prevalecía sobre el voto ciudadano que había rechazado el 21 de febrero de 2016 un referéndum de reforma constitucional que permitía la reelección presidencial indefinida, de tal manera que se pudo establecer que la soberanía se encontraba en la voluntad de los representantes del pueblo que, paradójicamente a su entender, representaban al pueblo ${ }^{7}$. Así se sostuvo en la referida decisión judicial:

Consiguientemente y conforme se acaba de constatar, la voluntad del constituyente, en relación a la reelección de la Presidenta o del Presidente y de la Vicepresidenta o Vicepresidente, fue decantarse por la reelección consecutiva por voluntad del pueblo; es decir, el constituyente originario consideró que no deberían establecerse límites a la posibilidad de que dichas autoridades puedan postularse nuevamente al cargo en ejercicio, pues la continuidad o no en el mismo dependía en todo caso de lo que determine la voluntad popular de brindarle o no, una vez más su confianza. (Tribunal Constitucional Plurinacionalista, Sentencia 0084)

7 El Tribunal Constitucional Plurinacional sostuvo en esa decisión que: “[...] si bien no corresponde excluir los demás métodos de interpretación constitucional existentes; empero, en todo caso y fundamentalmente, por mandato de la propia Constitución, se debe dar prioridad, a la voluntad de constituyente, reflejada en los documentos, actas y resoluciones de la Asamblea Constituyente, así como al tenor literal del texto" (Reelección Presidencial, 2017). 
Pero si la titularidad de la soberanía hubiese recaído en la asamblea constituyente, no se habría necesitado para la vigencia de la norma de un referéndum. En realidad, si la distinción entre poder constituyente y poder constituido se identifica por la soberanía del pueblo, entonces la asamblea constituyente no podía ser otra cosa que un poder constituido sometido a reglas de juego constitucionales establecidas por el pueblo. Asimismo, otro poder constituido como el Tribunal Constitucional Plurinacional no debería confundir al pueblo con una asamblea constituyente y manifestar que está sometido a un proyecto de constitución y no así a la Constitución aprobada por referéndum ${ }^{8}$.

En efecto, en Bolivia, la vigencia de la Constitución de 2009 se produjo recién luego del referéndum de 25 de enero de 2009 con el $61.43 \%$ de la votación aprobatoria, lo que significa 2064397 votos a favor y el $38.57 \%$ de votos contrarios; es decir, 1296175 personas votaron contra el nuevo texto ${ }^{9}$, por lo que la vigencia de la norma constitucional no se produjo fruto de la voluntad de asambleístas sino del voto del pueblo boliviano.

Incluso los orígenes de la teoría del poder constituyente nos muestran cómo Sieyes consideraba al poder constituyente no como un derecho positivo, sino natural, emergente — como ya se dijo- del derecho del pueblo a gobernarse a sí mismo y a imponerse normas, entre ellas una Constitución. Ese derecho correspondía al pueblo y de forma alguna a los asambleístas; algo que se desvirtuó por la asamblea constituyente francesa con la idea de la soberanía nacional. De ahí que, si bien la Constitución abrogada refería que el pueblo gobernaba de forma directa a través de la asamblea constituyente, solo y únicamente puede ser cierto como una ficción; incluso un aspecto tan claro como el referido no es claro en la Constitución de 2009.

8 El principal control al trabajo de la asamblea constituyente se encuentra en la ratificación por parte del electorado mediante referéndum del proyecto de Constitución.

9 Votaron efectivamente 3511681 ciudadanos, de los cuales, 3360571 fuero votos válidos, 59528 fueron votos en blanco y 91581 fueron votos nulos. 379635 personas se abstuvieron de votar, esto es el 9.76 \% del padrón electoral (Unión Europea, 2009). 
Pero habiéndose determinado que la teoría del poder constituyente boliviana se construye sobre el concepto de que el titular de la soberanía es el pueblo, resulta entonces relevante determinar cómo se compone ese pueblo; es decir: ¿quiénes fueron considerados como pueblo y, por tanto, como soberano en la redacción de la Constitución del año 2009 y debatieron con poder de decisión su contenido? La respuesta al interrogante en primera instancia debe atender a la consideración de a quiénes consideramos ciudadanos y a quiénes no, pues ello afecta la legitimidad del proceso ${ }^{10}$. A modo de ejemplo, se critica que en la primera Constitución de 1826 no se tomaron en cuenta a los campesinos e indígenas. En un diálogo sobre el poder constituyente, Carlos Mamani, un dirigente indígena, para sostener la falta de representación en la Asamblea Constituyente, afirmó:

El otro tema que me ha interesado es lo que dijo, un poco en tono de broma, el senador Böhrt: el tema de la autoría. Por fin, ¿Quién es el autor de la Constitución aprobada en Oruro? Porque creo que si somos honestos, es toda una proyección indigenista y no son realmente los propios indígenas los que la han escrito, lo digo muy claro aquí. ¿Quiénes han sido? Entonces, por ejemplo, si hablamos de autonomías indígenas, que es uno de los miedos y problemas que tenemos, hay un estudio que el РІЕв encomendó a unos dos o tres investigadores, y justamente ahí no encontramos ninguna propuesta indígena de autonomías, no hay desde los pueblos indígenas ninguna manifestación de ir por las autonomías. (Bonifaz y Ayo, 2008, p. 217)

Otra observación en la Constitución de 2009 radica en el hecho de que se excluyó del debate a niños, extranjeros, futuras generaciones y animales. Con respecto a aquellos considerados ciudadanos

10 La Constitución reformada en 2004 respecto al titular de la soberanía sostenía: “Artículo 2.- La soberanía reside en el pueblo; es inalienable e imprescriptible; su ejercicio está delegado a los poderes Legislativo, Ejecutivo y Judicial. La independencia y coordinación de estos poderes es la base del gobierno". De lo referido, el titular de la soberanía es pueblo; por ende, titular del poder constituyente. 
que podían votar, debió tomarse en cuenta que la inclusión no solo refiere a que el proyecto final de constitución mencione a ciertos sectores, o les reconozca ciertos derechos, entonces corresponde determinar si la elaboración del texto fue racional; en términos de Habermas, si fue incluyente en su elaboración, si les permitió —en este caso- a los indígenas y otro sectores vulnerables o minoritarios participar de forma que pudiesen incidir en el temario y en el contenido del texto constitucional.

\section{Sobre los contenidos tratados en la constituyente}

Una asamblea constituyente puede ser efectiva para reunir a los descontentos, pero no necesariamente unifica a un país, y tampoco toda promesa de cambio significa que el cambio va a ser necesariamente para bien ${ }^{11}$, de ahí que frente a una sensación de crisis en la población no solo sea necesario ser conscientes de la necesidad de una reforma constitucional, sino de saber exactamente qué se quiere reformar.

Si tenemos en cuenta que la determinación de qué debatir puede sesgar el debate democrático, se tiene que la constituyente boliviana de 2009 no fue transparente en el señalamiento del temario que debía tratarse, cuando, por ejemplo, se excluyó el reclamo del departamento de Chuquisaca referido a la capitalía plena (Universal, 2007), el aborto, entre otros. Esto significa que temáticas que necesitaban debatirse fueron sobreentendidas y se prescindió de un debate previo para determinar qué se debía debatir ${ }^{12}$.

En general, los debates constituyentes en Bolivia son a corto plazo, pues giran alrededor de la reelección presidencial, lo que opaca los debates a largo plazo. En este sentido, en la Constitución de 1826 o bolivariana, el presidente era irresponsable y

11 Recordemos que los cambios iniciados en su momento por los nacionalsocialistas se vieron como innovadores y progresistas.

12 Se recibieron las propuestas, pero fueron los constituyentes quienes terminaron por decidir qué se iba o no a debatir. 
vitalicio; en la Constitución de 1831, el presidente duraba en sus funciones cuatro años y podía ser reelegido; en la Constitución de 1843, el periodo presidencial pasó a ser de ocho años y el presidente no podía ser reelegido hasta pasado un periodo constitucional; en la Constitución de 1851, el periodo de presidente era de cinco años, sin reelección pasado un año; la Constitución de 1861 estableció que el presidente debía durar tres años sin poder ser reelecto, sino pasado un periodo; en la Constitución de 1868, el presidente era reelegido luego de cuatro años; la Constitución de 1871 estableció un periodo presidencial de cuatro años sin reelección; en la Constitución de 1931 se estableció la improrrogabilidad del periodo presidencial de cuatro años y solo después de dos periodos se podía volver a ser candidato; en la Constitución de 1945 se amplió el periodo presidencial a seis años; la Constitución de 1947 estableció un periodo presidencial de cuatro años y la posibilidad de reelección pasados cuatro años; en la Constitución de 1961 se estableció la reelección inmediata; en la Constitución de 1967 se permitió la reelección pasado un periodo constitucional, de donde se infiere que no es una casualidad que el elemento recurrente y más polémico en nuestra historia de procesos de reforma constitucional en Bolivia es el del tiempo de mandato presidencial y la reelección ${ }^{13}$, ello porque: 1) si el presidente y el parlamento son de la misma agrupación política, en general no hay separación ni control de poderes, porque siguen un mismo discurso, normalmente impuesto por el ejecutivo ${ }^{14}$; en cambio 2) si pertenecen a partidos políticos diferentes, en ese caso no hay gobernabilidad; por lo que por regla general se da el primer supuesto.

\footnotetext{
13 Para Serrafero, la combinación de: “[...] la reelección presidencial indefinida con un diseño institucional de presidencialismo fuerte no es la mejor de las opciones, sino el riesgo más cierto contra la vigencia auténtica de los derechos [...] el equilibrio de poderes y la estabilidad de las instituciones" (Serrafero, 2011).

14 A decir de Arguedas: "Los partidos políticos, que ni nombre tenían porque lo tomaban del mes en que se adueñaban del gobierno por medio de la revuelta absolutamente de programas, sin más fin ideal y principista que el de vencer para mandar [...]" por el placer sólo de mandar [...]" de forma que: "[...] militares y civiles maniobraban transigiendo con todo porque había llegado a ser norma del criterio colectivo la convicción de que las sanciones morales no tenían eficacia alguna y que lo importante era vencer porque la victoria borraba todas las faltas". (Arguedas, 1979).
} 
La Constitución boliviana del año 2009 fortaleció el presidencialismo al ampliar el tiempo de funciones del presidente a cinco años y al establecer la segunda vuelta y la reelección por una sola vez. Esta postura ya era criticada por implicar una desigual competencia por parte del presidente, quien tiene acceso directo a recursos públicos para presentar obras o comprometerlas a futuro, acceso a los medios de comunicación estatales, entre otras ventajas. Entonces, al no haber una democracia consolidada en Bolivia, no debatimos sobre salud, sobre libertad de expresión, entre otros, sino que el discurso y el debate de la reelección del gobernante de turno es permanente.

Por ello es posible sostener que hoy día sigue vigente el comentario de Arguedas sobre el presidencialismo, en sentido de que:

En esta lucha desmedida y apasionada, se dejan a un lado las ideas y el verdadero bienestar del país, y sólo se discute sobre la persona del gobernante y de sus ministros, siendo para unos lo mejor y lo peor para los otros [...]. (1979, p. 358)

Lamentablemente, con los años, este debate sigue empobreciendo a la opinión pública en Bolivia.

\section{Sobre la RACIONALIDAd DEL PROCEDIMIENTO DE REFORMA CONSTITUCIONAL}

En el análisis del profesor norteamericano Bruce Ackermann se diferencia entre los momentos de política constitucional y los momentos de política ordinaria. En este sentido, la política constitucional debería ser consciente y puede prolongarse a través de los años, lo que implica el rechazo a procesos rápidos e irracionales emergentes de la exaltación emocional del pueblo; es decir:

[...] la mayor parte de los estadounidenses identifican nuestras grandes luchas populares como procesos que culminan con los mayores logros constitucionales de la nación. Así, la 
Constitución original codificó la derrota de la monarquía por la generación revolucionaria en nombre del autogobierno republicano; las enmiendas de la Guerra Civil codificaron la lucha de toda una generación para rechazar la esclavitud en nombre de un nuevo ideal constitucional de igualdad, etcétera. En vez de olvidar estos logros populares, nuestra Constitución busca protegerlos de la erosión durante las épocas más normales, cuando el Pueblo se implica menos en asuntos de Estado. (Ackerman, 2015, p. 38)

Ahora bien, el proceso de reforma constitucional boliviano de 2009 no solo no ofreció garantías a la voz de las minorías ${ }^{15}$, sino que, al irrespetar el procedimiento de reforma constitucional, afectó al debate democrático. Así, en lo indígena, la Constitución de 2009 constituye la expresión de una acumulación histórica sobre esta temática; sin embargo, la falta de debate racional impidió que se traduzca en concreto, en normas consensuadas en el texto de la Constitución.

En efecto, el 22 de noviembre de 2007 la directiva de la asamblea constituyente convocó a una sesión en el Liceo Militar "Teniente Edmundo Andrade" cerca del palacio de la Glorieta y a cinco kilómetros de la ciudad de Sucre, donde aprobaron en grande el proyecto. Además, a raíz de la muerte de ciudadanos sucrenses frente a las fuerzas policiales y militares, el Congreso emitió la ley n. ${ }^{\circ} 3792$ de 28 de noviembre de 2007 modificando el artículo 6 de la ley n. ${ }^{\circ} 3364$, otorgando facultad a la presidenta de la asamblea para modificar la sede de funciones de la asamblea constituyente, para luego aprobarse en detalle en la ciudad de Oruro (Carrasco Alurralde, 2008).

Respecto al proyecto de constitución que se aprobó en grande el martes 27 de noviembre de 2007 en la ciudad de Sucre, sin debate

15 En noviembre de 2006, para la aprobación de la ley de tierras, y en el mes de febrero de 2008, para modificar la ley que regulaba la constituyente, hubo cerco social en la Plaza Murillo impidiéndose el ingreso de los opositores al recinto parlamentario, acto en esencia antidemocrático (Deheza, 2008). 
previo, entre enfrentamientos y muertos, y aprobado en detalle en Oruro el 9 de diciembre de 2007, sin que tampoco hubiese debate previo, resulta poco creíble que en un solo día se discutiera el contenido de los 410 artículos de la norma constitucional ${ }^{16}$.

En el mes de septiembre de 2008, en la ciudad de Cochabamba, se consensuaron diferentes modificaciones respecto al régimen autonómico ${ }^{17}$. Luego, el proyecto de constitución fue revisado por el denominado Congreso Constituyente del 20 al 21 de octubre de 2008 en La Paz y remitido después a un comité de redacción y estilo, que a su vez modificó el texto constitucional para presentarlo oficialmente el 14 de diciembre del mismo año, lo que denota que reformas importantes al texto se hicieron al margen del principio de publicidad.

En lo referente al procedimiento utilizado, se cree que el poder constituyente aparece de la nada, cuando en realidad el debate presupone reglas que organizan dicho debate, de ahí que la participación dependa de que los procedimientos sean participativos en la formulación del texto constitucional. El proceso de reforma constitucional no sostiene que la supremacía esté por encima o sea contraria a la soberanía popular, sino que la canaliza, la hace racional, meditada y consciente, entonces el voto popular no resuelve nada si el proyecto constitucional no es fruto de un debate racional.

Sin procedimientos que permitan el debate racional, el poder constituyente sería algo meramente fáctico, impuesto por la fuerza bruta. De acuerdo con Genaro Carrió, esa visión confundiría fuerza con potestad, de tal manera que es importante el cumplimiento del proceso de reforma constitucional, de modo que: “[...] puede afirmarse que la reforma no es una herramienta para la supresión de

16 A decir del profesor R. Gargarella: "[...] más que reivindicar la opción por reformas ambiciosas, podríamos afirmar que es preciso desconfiar de aquellas reformas que no incluyen ninguna reflexión seria acerca de las condiciones humanas y materiales en las que se basan" (Gargarella, 2014).

17 Se realizaron revisiones al texto constitucional con tres prefectos: Cossio de Tarija, Costas de Santa Cruz y Suarez del Beni. 
la constitución, sino que, pese a que suene paradójico, ella es una garantía de defensa" (Colombo Murúa, 2011). Sin un trámite y sin reglas que conduzcan el debate racional no podría haber consenso, todo sería anarquía.

\section{TEORÍA IMPURA DEL DERECHO DEVELA LA FALTA DE ACCIÓN COMUNICATIVA Y SE PROYECTA EN LA INTERPRETACIÓN CONSTITUCIONAL}

Respecto a la teoría impura del derecho, es ilustrativo el análisis que hizo el profesor colombiano Diego López Medina, cuando manifestó respecto a su experiencia personal que, a tiempo de formular su tesis doctoral, lo que había aprendido sobre Herbert Hart en su país natal no concordaba con la visión que tenían los profesores en una universidad productora de teoría jurídica. Esa enriquecedora experiencia hizo que replanteara su tema de tesis y analizara los trasplantes teóricos de un país productor de conocimiento jurídico a otro país receptor, para descubrir que la teoría migraba incompleta, no solo porque llegaba material sesgado, sino porque existe una recepción:

- retardada por la demora que existe en la traducción de textos jurídicos; y

- tergiversada por diferentes motivos, entre ellos: la falta de lectura de la obra completa de un profesor, deficientes traducciones y más aún la imposibilidad de traducir algunos términos al haberse ideado y desarrollado en una determinada realidad y cultura diferente a la que existe en el país en el que se pretende trasplantar; además, en general los docentes latinoamericanos no llegan a conocer personalmente a los profesores que leen.

Lo referido provoca que un profesor o juez enseñe o aplique una teoría muy diferente a la pensada en los centros de producción de teoría jurídica. Por ejemplo, hace la siguiente reflexión sobre el antiformalista Gény: 
[...] los juristas locales parecen haber leído Méthode mediante el despliegue de una interpretación selectiva que identificaba todos aquellos elementos que se conectaban con la cultura y el método jurídicos ya existentes, mientras que ignoraban aquellas partes y detalles (como su elemento científico) que resultaban excesivamente extraños o exóticos [...]. (López Medina, 2012, p. 275)

En un capítulo denominado Kelsen en Bogotá: Lecturas y usos locales de la Teoría Pura del Derecho, se muestra cómo la lectura del libro de Kelsen fue sesgada, cercenándose la parte antiformalista del libro que hacía referencia a la discrecionalidad:

La recepción de Kelsen, por tanto, no originó sensación de ruptura, sino más bien el placer de la confirmación de lo ya conocido. Esto resulta sumamente extraño ya que, si lo tomamos en sus textos mismos, el kelsenianismo es una teoría jurídica de choque que debió haber producido extrañeza y desazón, y no la, a veces, falsa familiaridad con la que se le observa localmente. (López Medina, 2012, p. 228) ${ }^{18}$

El discurso teórico — reflexiona - se tergiversa en las aulas de Derecho en América Latina, cuyos alumnos luego se vuelven jueces y docentes; de esa forma se reproduce constantemente.

Otras veces puede suceder que la impureza devenga del hecho de estudiar a prestigiosos profesores sin considerar el contexto en el que desarrollaron sus teorías, de forma que resuelven problemáticas emergentes de sus realidades, por lo que no funcionan en un contexto como el boliviano; de ahí que se acuse a los cientistas del derecho de hacer teorías genéricas que olvidan la realidad.

A continuación, se analizarán brevemente dos ejemplos en los cuales la falta de debate racional en la constituyente boliviana deriva en una teoría impura del derecho y se proyecta en la interpretación constitucional. 


\title{
5.1. EL PODER CONSTITUYENTE IRREGULAR EN LA JURISPRUDENCIA BOLIVIANA
}

Sobre el poder constituyente irregular, Sagüés (2016) nos dice que: “[...] es 'irregular' en el sentido de que no está obligado por reglas. En la segunda, porque ha violado reglas [...]" y que:

\begin{abstract}
En definitiva, pues, un poder constituyente originario puede ser entendido como "irregular", en una doble acepción: a) la primera, según una visión histórica ya superada, por no encontrarse bajo normas; b) la segunda, porque no es actualmente legibus solutus y puede padecer, claro está que en menor medida que el poder constituyente derivado, de defectos jurídicos de irregularidad (de forma y contenido). En particular, si colisiona con el derecho internacional, con sus propias reglas de autorregulación o con principios supranormativos. (Sagüés, 2016, p. 43)
\end{abstract}

Las deficiencias en la aprobación del texto constitucional boliviano pueden observarse en la jurisprudencia constitucional, específicamente en la impugnación del ejercicio del poder constituyente boliviano por irregular, porque la asamblea constituyente no podía ceder sus atribuciones en virtud de los artículos 2, 30, 31 y 228 de la Constitución abrogada al parlamento. Dicha irregularidad entonces se proyecta en definitiva a todo el texto constitucional y condice con la Sentencia Constitucional 0168/2010-R, en la cual se sostuvo que la asamblea constituyente boliviana fue originaria y no sometida o subordinada en forma alguna a los poderes constituidos. Se sostuvo por el órgano de control de constitucionalidad que:

[...] es imperante establecer el carácter de la Asamblea Constituyente en Bolivia y por tanto, determinar las reglas constitucionales a las cuales debe ser sometida, en tal sentido, es importante iniciar el análisis en la Ley Especial de Convocatoria a la Asamblea Constituyente, Ley 3364 de 6 de marzo de 2006, por tanto, se tiene que este acto normativo plasma la voluntad democrática pacífica para el cambio de orden constitucional, entonces, a partir de este acto, 
se establece que en Bolivia, la función constituyente tiene una génesis democrática no violenta, emergente de una grave crisis institucional, en consecuencia, a partir de esta manifestación democrática, se viabiliza el ejercicio de la función constituyente, la misma que tiene por objeto una reforma total de la Constitución y que emana de la soberanía popular, por tanto, esta labor no es propia de un Poder Constituyente derivado, sino más bien, es una verdadera función constituyente originaria, caracterizada por los tres rasgos esenciales descritos supra: su extraordinariedad, su extra-juridicidad y su autonomía. En consecuencia, evidentemente esta función por su naturaleza, no encuentra fundamento $n i$ vinculación jurídica en la Constitución, que pretende cambiar ni en los Poderes Constituidos emergentes de ese orden constitucional, postulado a partir del cual, se establece que las reglas a seguirse durante la vigencia extraordinaria de esta función; es decir en la etapa de elaboración de la nueva Constitución, serán la propia Ley 3364, y el Reglamento General de la Asamblea Constituyente. (Tribunal Constitucional Plurinacionalista, Sentencia 0168)

Empero, en otra decisión, manteniendo una postura incoherente, no da consecuencia a lo aseverado en sentido de la nulidad del proceso de reforma constituyente, y más bien en el auto constitucional n. ${ }^{\circ} 0532$ / 2010-CA correspondiente a una demanda respecto al procedimiento de reformas a la Constitución, ante diferentes denuncias sobre el irregular procedimiento de aprobación del texto constitucional, el Tribunal Constitucional se niega a ingresar al fondo de lo denunciado alegando que al haberse aprobado el proyecto constitucional a través del voto popular no correspondía hacerse un análisis de fondo alguno cuando ya lo habían hecho. Se sostuvo al respecto en la referida decisión:

En consecuencia, en el proceso de revolución constitucional que vivió Bolivia, como todo cambio transcendental, se enfrentó con una serie de hechos que fueron superados, por cuanto, es el pueblo soberano quien aprobó mediante referéndum, por mayoría de votos, la nueva Constitución Política del Estado, por lo que a estas alturas de su aplicación y vigencia resulta impertinente un 
análisis del procedimiento de reforma de la Constitución Política del Estado; es decir un análisis de fondo, por cuanto originaría una inseguridad jurídica, con una actitud en contra de la decisión soberana popular; en este sentido, el artículo 116 de la LTC — en actual vigencia - establece: "La demanda podrá ser planteada en cualquier momento, hasta antes de la sanción de la ley" [...]. (Tribunal Constitucional Plurinacionalista, Auto Constitucional 0532)

Entonces, los magistrados del órgano de control de constitucionalidad pretendieron de forma retroactiva reconstruir la narrativa de la asamblea constituyente, aunque no fueron coherentes en sus propias posturas y mantuvieron la vaguedad y las contradicciones del proceso constituyente, porque en su momento manifestaron que eran incompetentes para analizar el proceso de reforma constitucional durante e incluso luego de reformada la Constitución. Sin embargo, luego de presentada la demanda contra la normativa que impedía al presidente la reelección, se inaplicó la Constitución alegándose, entre otros, un defecto de competencia.

Habermas, con la teoría de la acción comunicativa, propone una teoría que permite explicar la interacción comunicativa, la conciliación de intereses y la solución de conflictos, la capacidad de autorreflexión, entre otros, todo de forma institucionalizada ${ }^{19}$. Así, los sujetos racionales no solo pueden conocer su realidad, sino que al mismo tiempo pueden cambiarla ${ }^{20}$. En este sentido, el profesor alemán cree que son racionales los que pueden aprender de sus errores y de los errores de los demás, pues solo lo racional puede ser criticado ${ }^{21}$.

19 "La propuesta habermasiana parte de facto de la base de que existe una comunicación racional que es más que un negociar de intereses individuales" (Radl Philipp, 1998).

20 “El orden moral es concebido por Habermas como el ámbito de conciliación de razón y voluntad, conocimiento y motivación, y por ello es el ámbito de la racionalidad en sentido pleno por excelencia" (Boladeras, 1996); la voluntad no es arbitraria, sino que es un imperativo racionalmente fundado, a diferencia de Kant, intersubjetivo.

21 “[...] se puede considerar que una persona es más o menos racional en función de su capacidad de enjuiciar las conductas y de tomar decisiones a partir de argumentos, así como de su capacidad de crítica y corrección de errores [...]" (Boladeras, 1996). 
Cuando el constituyente elabora una norma tan extensa como la Constitución boliviana con fundamentos implícitos, como sucede con el concepto de plurinacionalidad, de forma que una buena razón no pueda interiorizarse, entonces no puede discutirse "con" o criticarse "por" los otros.

Además, la politización del proceso constituyente, que impidió un debate racional, se viene proyectando a lo largo de los años dando primacía a la acción estratégica, lo que se observa en el desarrollo de lenguaje vacío por parte del Tribunal Constitucional Plurinacional como control plural de constitucionalidad o sentencias constitucionales plurinacionales, entre otros, o en el uso ambiguo o contradictorio de términos como sucede con el concepto de poder constituyente originario, que se entendía de manera ambigua y a conveniencia: como un poder sin límite jurídico alguno o como símbolo de participación indígena.

Habermas diferencia entre la conducta que refiere a los actos no reflexivos y la acción referida a las conductas y actos intencionales y que, por lo tanto, pueden entenderse. Una regla solo puede seguirse si se la entiende de manera que la idea de norma, en este caso constitucional, y la intencionalidad se relacionan en el lenguaje. El concepto de plurinacional no es propio de los pueblos indígenas, ni responde a su realidad; por ello mismo no tiene una traducción al quechua o al aymara. En este sentido, lo estamos inventando, pero el problema es el grado en el que al mismo tiempo lo estamos imponiendo.

\section{2. LA ACCIÓN DE CUMPLIMIENTO Y LA TEORÍA IMPURA DEL DERECHO EN Bolivia}

La constituyente boliviana fue significativamente influenciada por el proceso constituyente colombiano en su texto $\mathrm{y}$, fundamentalmente, por la jurisprudencia que emana de este. En este sentido, se atenderá a su texto en lo referente a la configuración de la acción de cumplimiento. 
El artículo 87 de la Constitución colombiana de 1991 establece: “Toda persona podrá acudir ante la autoridad judicial para hacer efectivo el cumplimiento de una ley o un acto administrativo. En caso de prosperar la acción, la sentencia ordenará a la autoridad renuente el cumplimiento del deber omitido" (Constitución Política de Colombia, 1991, Artículo 87).

Por su parte, la Constitución boliviana de 2009 en su artículo 135.I establece: "La Acción de Cumplimiento procederá en caso de incumplimiento de disposiciones constitucionales o de la ley por parte de servidores públicos, con el objeto de garantizar la ejecución de la norma omitida" (Constitución Política del Estado Plurinacional de Bolivia, 2009, Artículo 135.I).

Según parece, era llamativa al constituyente boliviano esta novísima figura procesal; sin embargo, no se entendió por qué alcanzaba a los actos administrativos, los cuales fueron excluidos del texto constitucional boliviano, introduciéndose entonces en su lugar el cumplimiento de la Constitución, aspecto per se ya controvertido en Colombia ${ }^{22}$ y que debió merecer cierto debate, el cual, conforme lo desarrollado ut supra, no se produjo.

La Constitución colombiana, al establecer la acción de cumplimiento, buscó hacer efectivo el derecho en su dimensión objetiva, dejando la defensa de la protección directa de los derechos subjetivos a la acción de tutela. Empero, en Bolivia y pese a la adopción de la figura, esta no fue entendida por el legislador ordinario a pesar de que algunos de los diputados y senadores incluso fueron constituyentes.

En desarrollo de la acción constitucional en el artículo 87 de la Ley del Tribunal Constitucional Plurinacional de 6 de julio de 2010, el legislador ordinario estableció que la acción de cumplimiento:

22 La sentencia C-651/03 de la Corte Constitucional de Colombia declaró exequible la regulación de la ley 393 de 1997 entendiendo que la configuración de la acción de cumplimiento no podía ampliarse al cumplimiento de la Constitución por el carácter indeterminado de las normas constitucionales. 
Tiene por objeto la defensa de los derechos constitucionales de las personas naturales o jurídicas, garantizando el cumplimiento del deber omitido por parte de los funcionarios o autoridades públicas, a lo ordenado por la Constitución Política del Estado o la ley.

Es decir, que se lo configuró como un amparo constitucional por omisión para proteger derechos subjetivos.

Pese a que la Constitución no establece un plazo de inmediatez de seis meses para la interposición de la acción de cumplimiento, o la subsidiariedad como requisitos, al ser configurado como un amparo constitucional por omisión, se incluyó esa configuración tergiversando el texto constitucional. Así, el artículo 88 de la ley del Tribunal Constitucional Plurinacional estableció: "Procederá en caso de incumplimiento de disposiciones constitucionales o de la ley, siempre que no existan vías administrativas o judiciales para su eficaz protección", pero al mismo tiempo generó un caos jurisprudencial al establecer en su artículo 89.1 su improcedencia: "Cuando los derechos omitidos puedan ser garantizados mediante acciones de Libertad, Amparo Constitucional, Protección de Privacidad y Popular".

El referido razonamiento fue compartido por los magistrados del Tribunal Constitucional Plurinacional, por ejemplo, mediante auto constitucional n. ${ }^{\circ}$ 0001/2012-RCA-SL-ACU de 11 de abril de 2012 se rechazó una acción de cumplimiento reprochando al accionante en sentido de que no debió: “[...] acudir directamente a la acción de cumplimiento pues una de sus características esenciales es la subsidiariedad".

Transcurridos los meses recién, los diputados y senadores al aprobar el Código Procesal Constitucional de 5 de julio de 2012 modificaron en el artículo 64 el objeto de la referida acción constitucional, al establecer: "La Acción de Cumplimiento tiene por objeto garantizar la ejecución de la norma constitucional o legal, cuando es omitida por parte de Servidoras o Servidores Públicos u Órganos del Estado", dirigiéndola al ámbito objetivo del 
derecho y dejando la afectación de los derechos subjetivos para el amparo constitucional, lo que denota la falta de debate del proceso constituyente boliviano.

\section{Conclusiones}

Una teoría impura del derecho, que en los hechos tiene los mismos resultados que la falta de teoría jurídica, impide que las personas puedan comunicarse entre sí; es decir, que al repetirse determinadas palabras contenidas en la Constitución, estas puedan más o menos saber a lo que se está refiriendo el interlocutor. Esto impide que el derecho cumpla su finalidad de proteger expectativas.

Lo referido explica por qué en actos públicos es posible observar alegorías detrás de las autoridades públicas, y mientras se solicita desesperadamente la unidad alrededor del líder de turno, se resalta a líderes indígenas como Tupac Katari junto a líderes republicanos como Pedro Domingo Murillo, como si fueran una continuidad, cuando en realidad históricamente uno niega al otro ${ }^{23}$. Lo anterior, claro está, si consideramos que el primero era un líder indígena que luchó no solo contra los españoles, sino contra los criollos, ofreciendo su vida no para erigir una Bolivia, sino para reconstituir la nación aymara, mientras que el segundo, es decir, Pedro Domingo Murillo, es visto como un líder de la independencia del Estado boliviano; por lo que se utiliza un discurso cultural impuro. Nuestra historia se muestra como si no hubiesen existido conflictos culturales, pero estos simplemente se esconden entre discursos patrióticos y conceptos genéricos como pueblo boliviano.

Si partimos de la idea de que la convivencia es intencional y no resultado de la suerte, entonces tenemos que una teoría impura del derecho o la falta de teoría que provoque vicios del consentimiento impide la convivencia. Así, por ejemplo, el discurso de muchos nacionalistas como Donald Trump muestra el problema

23 "No hay en Bolivia un epítome de 10 páginas y menos un libro que plantee y demuestre que Bolivia es una Nación” (Reinaga, 2005). 
de la inmigración como si fuera un problema cultural, cuando, en realidad, puede ser un problema económico, puesto que la gente migra porque no tiene otra alternativa. De esta manera el discurso cultural en ese caso encubre la verdadera problemática de la distribución de la riqueza entre Estados, y la falta de claridad en lo expuesto, en realidad, empeora el problema. Por ejemplo, en la lectura de Josef Estermann, muchos de nuestros problemas culturales son en realidad problemáticas políticas, económicas, entre otras, y no necesariamente culturales:

En Bolivia, el diálogo entre grupos "aolla" (del mundo andino aimara-quechua) y "camba" (del mundo oriental de Tierras Bajas) se ha tornado muy difícil, porque no es simplemente lo "cultural" que divide a los dos bandos, sino muchos prejuicios, una historia manipulada, una identidad bastante artificial (lo "aolla" y lo "camba" son construcciones recientes) y sobre todo intereses económicos y políticos (el manejo de las diferencias en provecho propio). Para encontrarse como grupos y personas, hay que mover primero muchos escombros (estereotipos, esquemas mentales, prejuicios, miedos, expectativas) que no realmente tiene que ver con las diferencias culturales de fondo. (Estermann, 2010, p. 57)

En términos de la teoría de la acción comunicativa desarrollada por el profesor Jürgen Habermas, la carencia de una teoría clara deviene de la falta de participación y el debate racional en el proceso de reforma constitucional, capaz de constituir una teoría jurídica clara que pueda criticarse o defenderse, pero que en definitiva permita en torno a ella el debate racional. En cuanto a la teoría del derecho, esta se edifica sobre controversias, pero incluso luego de publicada la Constitución, la falta de debate en Bolivia $^{24}$ impidió la construcción de una ciencia del derecho local.

Para Habermas, la comunicación implica el uso de expresiones lingüísticas comprensibles para los interlocutores y garantías de la

24 El debate argumentado entre profesores en Bolivia es muy poco común. 
pretensión de validez; es decir, según este autor, comprendemos algo si entendemos lo que lo hace aceptable ${ }^{25}$. Por lo tanto, se debe tener cuidado con la utilización de términos meramente emocionales que podrían ser esgrimidos por su novedad ${ }^{26}$, pues usamos el lenguaje para imponer una visión del mundo y por ello mismo debe ser resultado de una acción comunicativa.

El proceso constituyente boliviano estuvo lejos de las condiciones ideales de diálogo, de forma que la acción comunicativa se vio frustrada. Esto se demuestra en la medida en la que el texto constitucional, incluso para órganos tan especializados como son la asamblea legislativa plurinacional o el Tribunal Constitución Plurinacional, parece incomprensible.

\section{Referencias}

Ackerman, B. (2015). We the people I. Fundamentos de la historia constitucional estadounidense. IAEN - Instituto de Altos Estudios Nacionales de Ecuador.

Arguedas, A. (1979). Pueblo Enfermo. Editorial Gisbert \& Cia.

Boladeras, M. (1996). Comunicación ética y política. Habermas y sus críticos. Tecnos.

Bonifaz Moreno., G. y Ayo Saucedo, D. (2008). Taller Asamblea Constituyente: ¿hegemonía indígena o interculturalidad? Friedrich Ebert Stiftung.

Carrasco Alurralde, I. V. y Albo, X. (2008). Cronología de la Asamblea Constituyente. Tinkazos, 11(23-24), 101-128. https: / / bit.ly/3eyf5Xv

Constitución Política de Colombia. (1991). Artículo 87. https:/ / bit.ly /3vPTK2a

Constitución Política del Estado Plurinacional de Bolivia. (2009). Artículo 135.I. https: / bit.ly/3vMNZlH

Colombo Murúa, I. (2011). Límites a las reformas constitucionales: Teoría de las claúsulas pétreas. Poder constituyente y reforma cosntitucional. Constituciones rígidas, flexibles y pétreas. Análisis formal y análisis material. Reforma total. Doctrina y jurisprudencia. Argentina. Astrea.

Corte Constitucional de Colombia. (2003, 5 de agosto). Sentencia C-651/03 (Rodrigo Escobar Gil, M. P.). https: / / bit.ly/3f1UI55

25 "La teoría de la acción comunicativa quiere dar razón de los fundamentos normativos de una teoría crítica de la sociedad" (Boladeras, 1996).

26 “Puesto que el proceso discursivo no está concebido según el patrón de la movilización de las mejores razones, sino el de la fuerza de contagio de las expresiones que causan mayor impresión, no se puede hablar de 'fundamentación' [...]” (Habermas, 1999). 
Deheza, G. I. (2008). Bolivia: ¿Es posible la construcción de un nuevo Estado? La Asamblea Constitutuyente y las autonomías departamentales. Revista de Ciencia Política (Santiago), 28(1), 61-79. https: / / bit.ly / 3laiZHe

Estermann, J. (2010). Interculturalidad - Vivir la diversidad. ISEAT.

Gargarella, R. (2014). La sala de máquinas de la Constitución-Dos siglos de constitucionalismo en América Latina (1810-2010). Katz Editores.

Habermas, J. (1988). Teoría de la acción comunicativa. Tomo 1. Taurus.

Habermas, J. (1999). La inclusión del otro - Estudios de teoría política. Paidos.

Habermas, J. (2010). Facticidad y Validez. Trotta.

Landau, D. (2015). Derechos sociales y límites a la reforma constitucional: la influencia de la jurisprudencia de la Corte constitucional colombiana en el derecho comparado. Universidad Externado.

López Medina, D. (2012). Teoría Impura del Derecho. La transformación de la cultura jurídica latinoamericana. Legis.

Radl Philipp, R. (1998). La teoría del actuar comunicativo de Jürgen Habermas: un marco para el análisis de las condiciones socializadoras en las sociedades modernas. Papers. Revistas de Sociología, 56, 103-123. https: / / bit.ly/3eFcz1T

Redacción Internacional. (2007, 16 de septiembre). Las disputas por la capitalidad plena paralizan el proceso. El Universo. https: / / bit.ly/3lcSnWn

Reinaga, F. (2005). La revolución india. Ediciones Fundación Amáutica "Fausto Reynaga".

Sagüés, N. P. (2016). La Constitución bajo tensión. Instituto de Estudios Constitucionales del Estado de Querétaro.

Serrafero, M. (2011). La reelección presidencial indefinida en América Latina. Revista de Instituciones, Ideas y Mercados, 54, 225-259. https: / / bit.ly/2OOkkaG

Tribunal Constitucional Plurinacionalista. (2008, 29 de diciembre). Auto Constitucional 0532 / 2010-CA. https: / / bit.ly/3c9Dtxc

Tribunal Constitucional Plurinacionalista. (2010, 17 de mayo). Sentencia Constitucional Plurinacional 0168 (Ligia Mónica Velásquez Castaños, M. P.). https: / / bit.ly/3vNa03W

Tribunal Constitucional Plurinacionalista. (2017, 28 de noviembre). Sentencia Constitucional Plurinacional 0084 (Macario Lahor Cortez Chavez, M. R.). https: / / bit.ly / 3sasWXQ

Tapia, L. (2002). La condición multisocietal. Editorial Muela del Diablo.

Unión Europea. (2009). Informe Final. Referéndum Nacional Constituyente. https: / / bit.ly/3cmHBsq

Vega García, P. (1998). Mundialización y derecho constitucional: la crisis del principio democrático en el constitucionalismo actual. Revista de Estudios Políticos, 100, 13-56. https: / / bit.ly/3rKGM31 